Correspondence: Frédéric Gagnadoux, Département de Pneumologie, CHU, 4 rue Larrey, 49033 Angers Cedex 9, France. E-mail: frgagnadoux@chu-angers.fr

Received: Feb 262013 | Accepted: Mar 302013

Conflict of interest: Disclosures can be found alongside the online version of this article at www.ersjournals.com

Acknowledgements: The IRSR sleep cohort group members: F. Gagnadoux, N. Meslier, C. Person (Centre Hospitalier Universitaire, Angers); F. Goupil, O. Molinier (Centre Hospitalier, Le Mans); A. Bizieux-Thaminy, P. Breton, K. Berkani (Centre Hospitalier, La Roche sur Yon); T. Pigeanne (Pôle santé des Olonnes, Olonne sur Mer); S. Chollet, S. Jaffre, F. Corne, M. Boeffard, B. Nogues (Centre Hospitalier Universitaire, Nantes); M.P. Humeau (Nouvelles Cliniques Nantaises); C. Kierzkowski (M Normand de la Tranchade); J.L. Racineux, C. Gosselin (ALTADIR); M. Le Vaillant, N. Pelletier-Fleury (CERMES, CNRS UMR8211 - Inserm U988 - EHESS, Site CNRS).

\title{
References
}

McArdle N, Devereux G, Heidarnejad H, et al. Long-term use of CPAP therapy for sleep apnea/hypopnea syndrome. Am J Respir Crit Care Med 1999; 159: 1108-1114.

2 Gagnadoux F, Le Vaillant M, Goupil F, et al. Influence of marital status and employment status on long-term adherence with continuous positive airway pressure in sleep apnea patients. PLoS One 2011; 6: e22503.

3 Trzepizur W, Le Vaillant M, Meslier N, et al. Independent association between nocturnal intermittent hypoxemia and metabolic dyslipidemia. Chest 2013; 143: 1584-1589.

4 Bixler EO, Vgontzas AN, Lin HM, et al. Excessive daytime sleepiness in a general population sample: the role of sleep apnea, age, obesity, diabetes, and depression. J Clin Endocrinol Metab 2005; 90: 4510-4515.

5 McKee MM, Winters PC, Fiscella K. Low education as a risk factor for undiagnosed angina. J Am Board Fam Med, 25: 416-421.

6 Young T, Finn L, Peppard PE, et al. Sleep disordered breathing and mortality: eighteen-year follow-up of the Wisconsin sleep cohort. Sleep 2008; 31: 1071-1078.

7 Mazza S, Pépin JL, Naëgelé B, et al. Most obstructive sleep apnoea patients exhibit vigilance and attention deficits on an extended battery of tests. Eur Respir J 2005; 25: 75-80.

8 Barbé F, Durán-Cantolla J, Sánchez-de-la-Torre M, et al. Effect of continuous positive airway pressure on the incidence of hypertension and cardiovascular events in nonsleepy patients with obstructive sleep apnea: a randomized controlled trial. JAMA 2012; 307: 2161-2168.

9 Craig SE, Kohler M, Nicoll D, et al. Continuous positive airway pressure improves sleepiness but not calculated vascular risk in patients with minimally symptomatic obstructive sleep apnoea: the MOSAIC randomised controlled trial. Thorax 2012; 67: 1090-1096.

10 Silverman SL. From randomized controlled trials to observational studies. Am J Med 2009; 122: 114-120.

\section{Severe acute respiratory distress syndrome due to ipilimumab}

To the Editor:

Ipilimumab is a T-cell-potentiating human monoclonal antibody against cytotoxic T-lymphocyteassociated antigen (CTLA)-4, which promotes antitumour immunity by unrestrained T-cell activation [1]. It is the first agent shown to improve survival in patients with metastatic melanoma [2]. However, various ipilimumab-associated immune-related adverse events including enterocolitis, dermatitis, hepatitis, hypophysitis, meningo-radiculo-neuritis, and renal failure have been reported [3]. The few reported cases of pulmonary side-effects consist of ipilimumab-induced sarcoid-like granulomatosis [4-7]. To our knowledge, this is the first report of an ipilimumab-induced lung injury presenting as severe acute respiratory distress syndrome (ARDS).

A 64-year-old former smoker with metastatic melanoma (stage IIIC) was referred with hypoxaemic respiratory failure and oedema of both feet and hands, following administration of the second dose of ipilimumab (246 mg) 4 days earlier. After the first dose $(237 \mathrm{mg})$, given 6 weeks earlier in combination with radiotherapy for inguinal lymph node metastases and topical immunotherapy with diphenylcyclopropenone $0.1 \%$ for cutaneous metastases, the patient presented with generalised exanthema in the absence of respiratory symptoms, which was responsive to oral and topical steroids. His past medical history was uneventful for pulmonary diseases, and he took no drugs other than ipilimumab and prednisone $\left(30 \mathrm{mg} \cdot \mathrm{day}^{-1}\right)$ for exanthema. He was tachycardic $\left(120 \mathrm{beats} \cdot \mathrm{min}^{-1}\right)$ and normotensive. His respiratory rate was 34 per min and a peripheral cyanosis was present. The jugular veins were not distended, but marked oedema of both the feet and hands were present. Cardiac auscultation was unrevealing, but bilateral crackles 
were audible over both lungs. The results of laboratory studies were only remarkable for elevated C-reactive protein $\left(84 \mathrm{mg} \cdot \mathrm{L}^{-1}\right)$, whereas procalcitonin was $0.23 \mu \mathrm{g} \cdot \mathrm{L}^{-1}$, and pro-brain natriuretic peptide was $508 \mathrm{ng} \cdot \mathrm{L}^{-1}$. The leukocyte count was $4.4 \times 10^{9} \cdot \mathrm{L}^{-1}$, with $0.7 \%$ eosinophils. A chest computed tomography revealed obvious signs of diffuse parenchymal lung disease (fig. 1). Bronchoalveolar lavage was avoided due to severely impaired oxygenation (arterial oxygen saturation measured by pulse oximetry $80 \%$, arterial oxygen tension $\left(\mathrm{PaO}_{2}\right) 45 \mathrm{mmHg}$ and arterial carbon dioxide tension $33 \mathrm{mmHg}$ while breathing $100 \%$ inspiratory oxygen fraction $\left(\mathrm{FIO}_{2}\right)$ over a Venturi mask, $\left.\mathrm{PaO}_{2} / \mathrm{FIO}_{2} 45 \mathrm{mmHg}\right)$. Echocardiography was normal. The patient was treated empirically with piperacillin/tazobactam ( $4.5 \mathrm{~g}$ three times daily), trimethoprim/sulfamethoxazole $(320 \mathrm{mg} / 1.6 \mathrm{~g}$ every $6 \mathrm{~h})$ and methylprednisolone $\left(500 \mathrm{mg} \cdot \mathrm{day}^{-1}\right)$. Sputum samples, blood cultures and urinary legionella antigen testing were all negative. Since there were no clinical or serological findings suggesting an autoimmune disease and the patient fulfilled the Berlin definition for ARDS, ipilimumab-induced lung injury presenting as ARDS was presumed. The treatment was continued with methylprednisolone $\left(125 \mathrm{mg} \cdot \mathrm{day}^{-1}\right)$, once daily, for the following 3 days and prednisone $\left(80 \mathrm{mg} \cdot \mathrm{day}^{-1}\right.$, corresponding to $\left.1 \mathrm{mg} \cdot \mathrm{kg}^{-1} \cdot \mathrm{day}^{-1}\right)$ thereafter. He received trimethoprim/sulfamethoxazole Pneumocystis jirovecii prophylaxis. The patient subsequently recovered with slowly improving oxygenation. After 2 months, oxygen supplementation therapy could be stopped and the prednisone dose could be tapered to $10 \mathrm{mg} \cdot \mathrm{day}^{-1}$. Pulmonary function tests had also improved to near normal values (forced vital capacity $71 \%$, forced expiratory volume in $1 \mathrm{~s} 78 \%$, total lung capacity $66 \%$, diffusing capacity of the lung for carbon monoxide $52 \%$ predicted). Although partial metabolic and morphological response to ipilimumab has been stated 40 days after the second ipilimumab dose, it was no longer administered after the second dose, and progressive metastatic melanoma was found within 4 months.

Ipilimumab acts by an enhanced T-cell activation and proliferation with subsequent lymphocyte-mediated death of tumour cells, which is determined by inhibiting CTLA-4 [1]. Several ipilimumab-associated immune-related adverse events have been described. Thus, guidelines for the management of such events are provided [3]. Most of the side-effects are considered of a mild or moderate degree, with dermatitis (up to $43 \%$ ) and enterocolitis (30\%) being the most frequent entities. Aside from ipilimumab-induced sarcoidlike granulomatosis of the lung [4-7], reports on pulmonary toxicity are not available. In a randomised, double-blind, phase three study enrolling 511 patients with stage III or IV melanoma treated with ipilimumab $12.7 \%$ reported dyspnoea and $0.6 \%$ experienced severe dyspnoea [2]. However, no detailed information on the subject's characteristics or outcomes is available.

Our patient recovered partially from the severe ARDS, which was most likely caused by ipilimumab after other aetiologies, i.e. other potentially pneumotoxic drugs, relevant comorbid conditions (e.g. left heart failure) or infection, had been excluded. However, since ipilimumab therapy was terminated and the patient received both high dose corticosteroids and antibiotics, drug-induced lung disease cannot be ascertained. Infection, including $P$. jirovecii, cannot be excluded definitely, but seemed unlikely, as the sputum smear was negative. Whether the high doses of corticosteroids were responsible for the functional improvement remains speculative. Besides the former smoker status (3 years since cessation, cumulative 30 pack-years), our patient had no pulmonary comorbidities, which would eventually enhance the risk of pulmonary sideeffects. But, it is possible that the simultaneous irradiation therapy contributed to provoke the severe pulmonary toxicity (abscopal effect) [8]. Our observation strongly suggests that ipilimumab may cause

FIGURE 1 Chest computed tomography with several signs of diffuse parenchymal lung injury including extensive ground-glass opacities and micronodular changes.

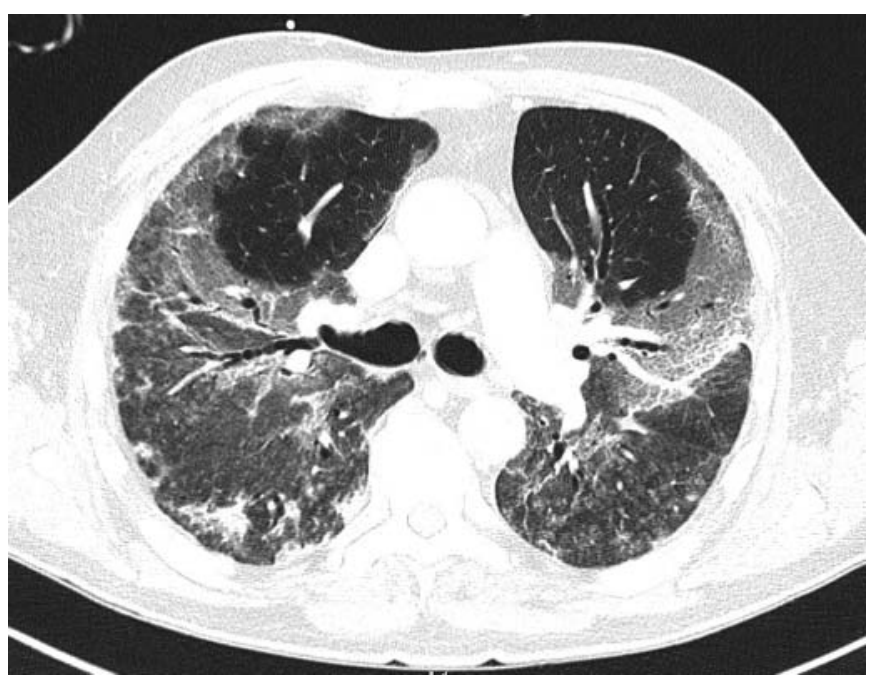


non-infectious lung injury similar to other immunomodulatory agents (i.e. rituximab, golimumab, and tocilizumab). We expect that such events will be observed more frequently, since this agent will continue to be used for the treatment of metastatic melanoma, and in small and nonsmall cell lung cancer in the near future $[9,10]$.

\section{- @ERSpublications \\ The first report of an ipilimumab-induced lung injury presenting as severe acute respiratory distress syndrome http://ow.ly/mxgC6}

Daniel Franzen ${ }^{1}$, Karin Schad ${ }^{2}$, Reinhard Dummer ${ }^{2}$ and Erich W. Russi ${ }^{1}$

${ }^{1}$ Dept of Respiratory Medicine, University Hospital Zurich, Zurich, and ${ }^{2}$ Dept of Dermatology, University Hospital Zurich, Zurich, Switzerland.

Correspondence: D. Franzen, Dept of Respiratory Medicine, University Hospital Zurich, Raemistrasse 100, 8091 Zurich, Switzerland. E-Mail: daniel.franzen@usz.ch

Received: March 122013 | Accepted: March 222013

Conflict of interest: Disclosures can be found alongside the online version of this article at www.erj.ersjournals.com

\section{References}

1 Culver ME, Gatesman ML, Mancl EE, et al. Ipilimumab: a novel treatment for metastatic melanoma. Ann Pharmacother 2011; 45: 510-519.

2 Hodi FS, O'Day SJ, McDermott DF, et al. Improved survival with ipilimumab in patients with metastatic melanoma. N Engl J Med 2010; 363: 711-723.

3 Andrews S, Holden R. Characteristics and management of immune related adverse effects associated with ipilimumab, a new immunotherapy for metastatic melanoma. Cancer Manag Res 2012; 4: 299-307.

4 Eckert A, Schoeffler A, Dalle S, et al. Anti-CTLA4 monoclonal antibody induced sarcoidosis in a metastatic melanoma patient. Dermatology 2009; 218: 69-70.

5 Berthod G, Lazor R, Letovanec I, et al. Pulmonary sarcoid-like granulomatosis induced by ipilimumab. J Clin Oncol 2012; 30: e156-e159.

6 Wilgenhof S, Morlion V, Seghers AC, et al. Sarcoidosis in a patient with metastatic melanoma sequentially treated with anti-CTLA-4 monoclonal antibody and selective BRAF inhibitor. Anticancer Res 2012; 32: 1355-1359.

7 Tissot C, Carsin A, Freymond N, et al. Sarcoidosis complicating anti-cytotoxic T-lymphocyte-associated antigen-4 monoclonal antibody biotherapy. Eur Respir J 2013; 41: 246-247.

8 Postow MA, Callahan MK, Barker CA, et al. Immunologic correlates of the abscopal effect in a patient with melanoma. N Engl J Med 2012; 366: 925-931.

9 Tomasini P, Khobta N, Greillier L, et al. Ipilimumab: its potential in non-small cell lung cancer. Ther Adv Med Oncol 2012; 4: 43-50.

10 Reck M, Bondarenko I, Luft A, et al. Ipilimumab in combination with paclitaxel and carboplatin as first-line therapy in extensive-disease-small-cell lung cancer: results from a randomized, double-blind, multicenter phase 2 trial. Ann Oncol 2013; 24: 75-83. 